\title{
Affinity of liver cells to Sudanophilia and PAS in castrated treated mice
}

\begin{abstract}
The present study was conducted on seventy five healthy males of Swiss albino mice, which were divided into 5 groups $(\mathrm{N}=15$ mice per each group). The first group were intact (control); the second one were castrated; the third group were castrated treated with $50 \mu \mathrm{g} /$ $\mathrm{kg}$ testosterone; the forth one were castrated treated with $10 \mu \mathrm{l} / \mathrm{g}$. grape juice, and the fifth one were intact treated with $3 \mathrm{mg} / \mathrm{kg} \mathrm{F}$. hormonis.

The frozen sections ofmice liver tissue from both castrated and intact treated subjects with $3 \mathrm{mg} / \mathrm{kg}$ Ferula hormonis showed a strong affinity to sudanophilia $(+++)$ as compared with the intact (control) group. Whereas frozen sections from castrated subjects treated with $50 \mu \mathrm{g} / \mathrm{kg}$ of testosterone or with $10 \mu \mathrm{l} / \mathrm{g}$ of grape juice showed a moderate affinity to sudanophilia (++) as compared with the control. The histological sections of liver tissue from castrated group or intact treated with $3 \mathrm{mk} / \mathrm{kg}$ F. hormonis revealed a decrease in glycogen contents as compared with the control group. On the other hand, sections from castrated subjects treated with $50 \mu \mathrm{g} / \mathrm{kg}$ of testosterone or with $10 \mu \mathrm{l} / \mathrm{g}$ of grape juice appeared normal appearance to intact (control) subjects
\end{abstract}

Volume 7 Issue 5 - 2020

\author{
Homady MH,' Alquraishi LO, ${ }^{2}$ Ali M \\ Hussein, ${ }^{3}$ Omar Fikrat ${ }^{3}$ \\ 'College of Science, Department of Biomedical Sciences, Cihan \\ University, Erbil, Kurdistan region, Iraq \\ ${ }^{2}$ College of Dentistry, Babylon University, Iraq \\ ${ }^{3}$ College of Science, Department of General Biology, Cihan \\ University, Erbil, Kurdistan region, Iraq
}

Correspondence: Homady MH, College of Science,

Department of Biomedical Sciences, Cihan University, Erbil,

Kurdistan region, Iraq, Tel +96475 I7। I8678,

Email mrzahomady@cihanuniversity.edu.iq

Received: October 18,2020 | Published: October 27, 2020

Keywords: sudanophilia, liver, lipids, glycogen, ferula hormonis

\section{Introduction}

The mammalian liver is the largest internal digestive organ, morphologically and functionally is a complex digestive gland, which is indispensable in many essential physiologic processes and vulnerable to be impaired by a wide variety of factors, such as toxins, microorganisms, metabolic products, circulatory materials and metabolism of carbohydrates, lipids and proteins. ${ }^{1,2}$ It is made up of the largely predominant parenchymal cells (hepatocytes), and also non-parenchymal cells, including Ito (perisinusoidal cells), Kupffer cells and sinusoidal endothelial cells. ${ }^{3,4}$

Surgical castration is a bilateral (excision of both testes) removal of testis, resulted in depletion of androgen ${ }^{5,6} \mathrm{Farm}$ animals have been castrated to eliminate breeding and reduce aggressive behavior. ${ }^{7,8}$ Hypogonadism after castration caused abdominal obesity, impaired fasting glucose, excess accumulation of liver triglyceride, and thigh muscle loss. Castration also induced increase of visceral fat mass and decreased thigh muscle mass in mice. ${ }^{9}$ Castration is a way of studying the consequences of extreme testosterone deficiency in animal models. ${ }^{10}$ Testosterone suppresses ER stress, inhibits the formation of macrovesicular lipid droplets, promotes lipid export, and ameliorates steatohepatitis induced by castration. ${ }^{11}$

The primary and most well-known androgen is testosterone which is the product of dihydrotesterone (DHT). Serum testosterone levels decline gradually and progressively with aging in men. Low levels of testosterone are associated with metabolic disorders, including obesity, dyslipidemia, hypertension, and insulin resistance. ${ }^{12-15}$ The degree of insulin resistance correlates negatively with serum testosterone ${ }^{16,17}$ and low serum testosterone levels have a higher risk of developing hepatic steatosis. ${ }^{18}$

The anti-fertility activities of medicinal plants have been extensively investigated in mice and rats. ${ }^{19}$ Several species of these plants were reported to have estrogenic activity while few of them show significant contraceptive properties. ${ }^{20}$ Phytoesterogenic are novel esteron found in a variety of plants which may be ingested directly as constituent tissues from animals that have digested plant phytoestrogen, have noxious effect leading to infertility in domestic animals as well as disturbance of normal gestation processes. There are a number of phytoestrogen plants likely to be consumed by human such as Ferula hormonis, the toxic effect of Ferula in cattle is associated with hemorrhage disease probably due to ferulenol, fepernin, 4-hydroxylated, and prenylated coumarins. ${ }^{20}$ Some medicinal plants may exert promising pharmacological properties and improve the effectiveness of conventional medications as complementary agents. ${ }^{21}$

Vitisvinifera (Grape) are one of the most consumed fruits globally. It possesses a wide range of pharmacological activities due to its rich polyphenol ingredients most of which have been demonstrated to have therapeutic or health promoting properties, ${ }^{22-24}$ among them, flavonoids are the most abundant and widely studied, recent studies have shown that the beneficial health effects promoted by consumption of grape and grape products are attributed to the unique mix of polyphenolic compounds. As the largest group of grape polyphenols, flavonoids are the main candidates considered to have biological properties, including but not limited to antioxidant, antiinflammatory, anti-cancer antimicrobial, antiviral, cardio protective, neuroprotective and hepatoprotective. ${ }^{25-27}$ Therefore the present study is aimed to study the affinity of hepatocytes to sudanophilia and to determine the quantity of glycogen contents in hepatocytes cells in different surgical and physiological conditions such as:-castration, castration treated with testosterone, or grape juice as well asin intact animal treated with F. hormonis.

\section{Materials and methods}

Swiss albino male mice weighting between (14-17) g., and aged (3weeks) were used in the present study, the mice were obtained from 
the Animal House, Faculty of Science/ University of Kufa. Animals were kept in ventilated cages, with a temperature of $\left(25 \pm 2^{\circ} \mathrm{C}\right)$ at $12: 12 \mathrm{~h}$ light, dark cycle was used balanced, rodent food pellet and water were provided ad libitum..$^{28}$ All experimental protocols using live animals were first reviewed, approved and accepted according to guidelines for the care and use of laboratory animals in biomedical research. ${ }^{29,30}$

A total number of 75 Swiss albino mice were used in the present study. Animals were divided into 5 groups $(\mathrm{N}=15)$, and the treatment was started at the age of 21 days for 6 weeks as:

Group I: Intact male mice received tap-water as control.

Group II: Castrated male mice received tap-water as (positive group).

Group III: Castrated male mice treated daily with $50 \mu \mathrm{g} / \mathrm{kg}$ testosterone.

Group V: Castrated male mice treated daily with $10 \mu \mathrm{l} / \mathrm{g}$. grape juice,

Group IV: intact male mice treated with $3 \mathrm{mg} / \mathrm{kg}$ F. hormonis.

The surgical castration method was done according to $^{31}$

Testosterone dose Selection: A previous study documented that $50 \mu \mathrm{g} / \mathrm{kg} /$ day of the testosterone solution was not toxic, ${ }^{31}$ for the present protocol, $50 \mu \mathrm{g} / \mathrm{Kg} /$ day was used in the present study. This dose is given daily as intramuscularly on consecutive thigh muscle for six weeks.

\section{Plant material extract}

Black grape (Vitisvinifera) obtained from local market (Baghdad, Iraq) $100 \mathrm{~g}$ of grape was blundered by using a commercial blender without separating the seeds, and then it was filtered to remove the residue. The resulting extract $(10 \mathrm{mls})$ was stored in the refrigerator at $4^{\circ} \mathrm{C}$., and used after one hour. The extract was prepared according to. ${ }^{32}$ A previous study documented that $10 \mu \mathrm{l} / \mathrm{g} /$ day of grape juice extract was effective dose ${ }^{33-35}$ For this protocol, we used in the present study $10 \mu \mathrm{l} / \mathrm{g} /$ day and was given daily as orally administered for six weeks.

\section{Ferula hormonis}

Roots were obtained from a local market in (Amman, Jordan), the extract material was prepared according to the procedure described by $^{32}$ In the course of the experiments ( $\left.3 \mathrm{~g}\right)$ of the residue was dissolved in $100 \mathrm{mls}$ of distilled water and $3 \mathrm{mg} / \mathrm{kg}$ were used.

Animals were sacrificed at the end of the experiments, with using ketamine and xylazine as anesthetic drugs to anesthetize the mice.The preparation procedures for frozen sections and Periodic Acid Schiff (PAS) have been described by. ${ }^{32}$ The frozen sections were stained by using Sudan black B.

\section{Digital analysis}

Digital analysis was performed using image $\mathbf{J}$ software. Digital of lipid droplets in frozen section stained with Sudan black B. ${ }^{36,37}$ Results were expressed as the mean \pm standard deviation of the mean (S.D). Data for multiple variable comparisons were analyzed by one-way analysis of variance (ANOVA). For the comparison of significance between groups, Duncan's test was used as a post hoc test according to the statistical package program (SPSS version 16.0) the $p$ values $\mathrm{P}<0.05$ was considered as significant for all statistical analysis in this study.

\section{Results}

The present results of Table 1 show the scoring number of Sudanophilia in different experimental groups. Figure 1 representing frozen sections from intact (control) male mice stained with Sudan Black B showing a weak affinity to Sudanophilia (+).Whereas sections from both castrated and intact subjects treated with $3 \mathrm{mg} / \mathrm{kg}$ F. hormonis (Figure $2 \& 3$ ) showed a strong affinity to Sudanophilia $(+++)$ as compared with control group. On the other hand frozen sections from castrated subjects treated with $50 \mu \mathrm{g} / \mathrm{kg}$ testosterone or castrated treated with $10 \mu \mathrm{l} / \mathrm{g}$ grape juice (Figure $4 \& 5$ ) showed a moderate affinity to Sudanophilia (++) as compared with control.

Liver glycogen detection: By using Periodic Acid Schiff (PAS) stain the histological sections of liver tissue from intact male mice (Figure 6) showed a normal glycogen contents. However, the histological sections of liver tissue from castrated (Figure 7) and intact group treated with $3 \mathrm{mg} / \mathrm{kg}$ of $\mathrm{F}$. hormonis (Figure 8) appeared a decrease in the amount of glycogen contents as compared with the control subject. Whereas the histological sections from castrated group treated with $50 \mu \mathrm{g} / \mathrm{kg}$ testosterone (Figure 9) as well as, castrated group treated with $10 \mu \mathrm{l} / \mathrm{g}$ grape juice (Figure 10) showed return the glycogen contents to the normal state as compared with the control group.

Table I Showing the scoring number of Sudanophilia in different experimental groups of male mice

\begin{tabular}{|c|c|c|c|}
\hline A (percentage of positive cells) & B (intensity of staining) & score (multiplication of A and B) & Power \\
\hline $0=$ no positive cells & $0=$ no color reaction & $0-I=$ negative & 0 poor \\
\hline$I=<10$ of positive & $I=$ mild reaction & $2-3=$ mild & + weak \\
\hline $2=10-20$ positive cells & $2=$ moderate reaction & $4-8=$ moderate & ++ moderate \\
\hline $3=21-50$ positive cells & $3=$ intense reaction & $9-12=$ strongly positive & +++ strong \\
\hline $4=>50$ & Final IRS score $(A \times B): 0-12$ & & \\
\hline
\end{tabular}




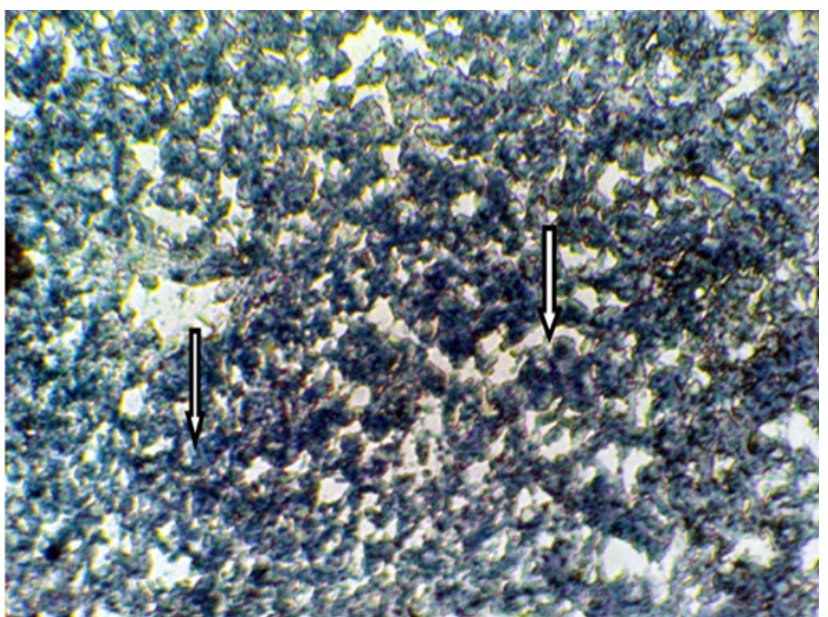

Figure I Frozen section of liver tissue from intact male mice stained with Sudan Black B showing a weak affinity to Sudanophilia (+), arrow indicated lipid droplets (X400).

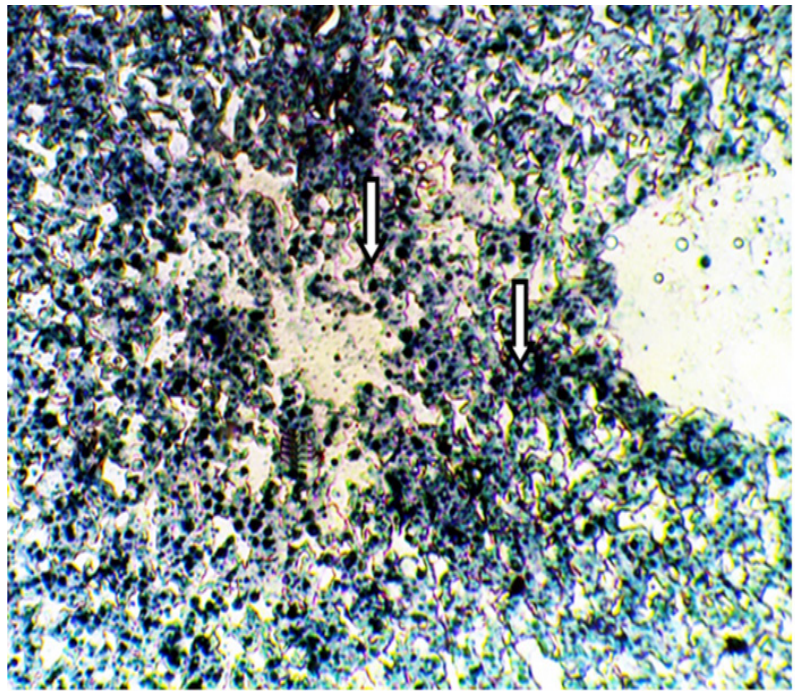

Figure 2 Frozen section of liver tissue from castrated male mice showing strong affinity to Sudanophila (+++), arrow indicated lipid droplets (X400).

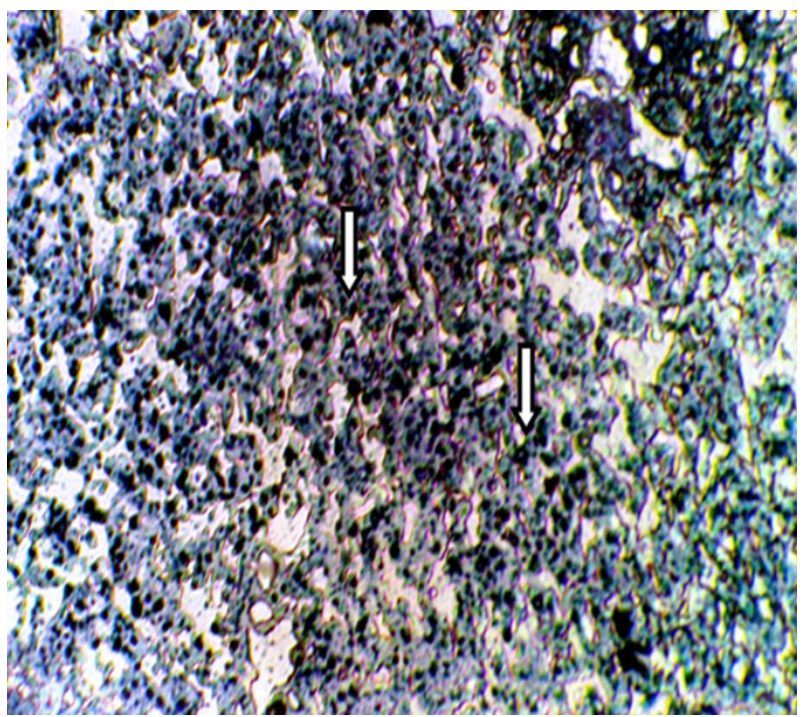

Figure 3 Frozen section of liver tissue from intact mice treated with $3 \mathrm{mg} / \mathrm{kg} \mathrm{F}$ hormones stained with Sudan Black B showing a strong affinity to Sudanophilia $(+++)$, arrow indicated lipid droplets (400X).

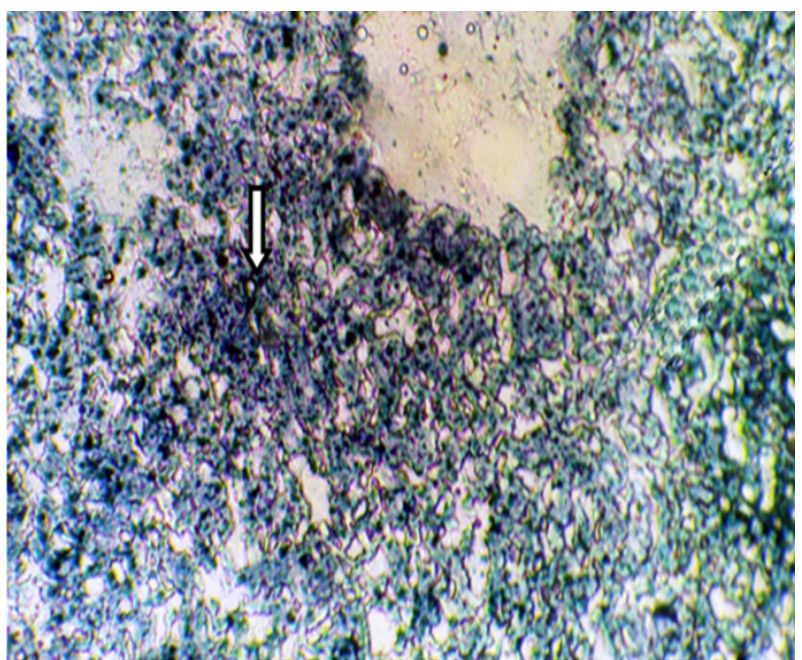

Figure 4 Frozen section of liver tissue from castrated subject treated with $50 \mu \mathrm{g} / \mathrm{kg}$ testosterone showing a moderate affinity to Sudanophilia (++), arrow indicated lipid droplets (X400).

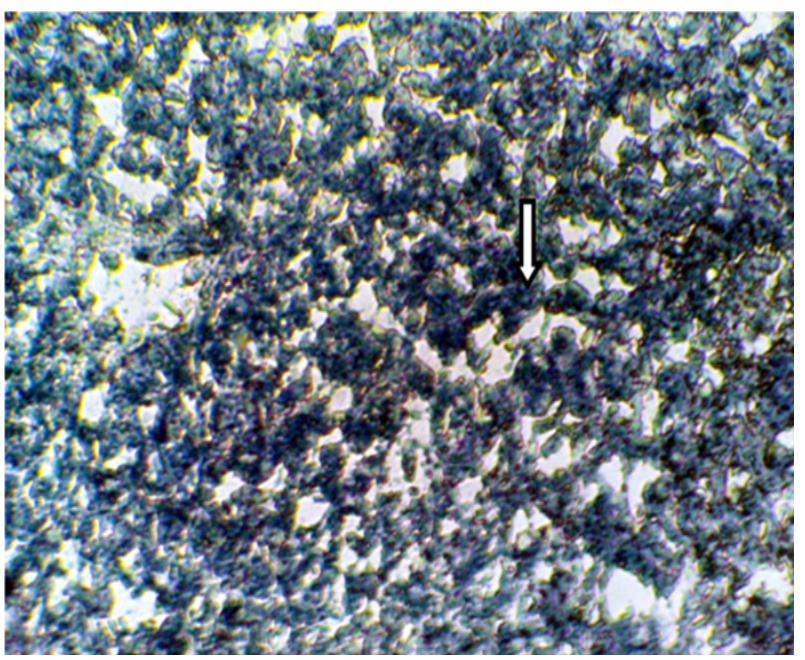

Figure 5 Frozen section of liver tissue from castrated mice treated with 10 $\mu \mathrm{l} / \mathrm{g}$ grape juice showing a moderate affinity to Sudanophilia $(++)$, arrow indicated lipid droplets (X400).

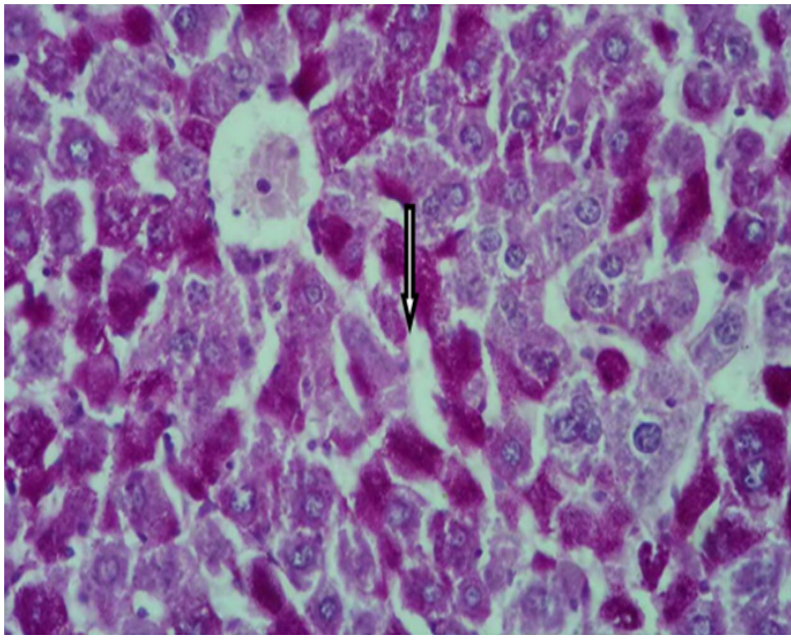

Figure 6 Cross histological section of liver tissue from intact male mice Stained with PAS showing normal glycogen contents, arrow indicated glycogen contents $(X 400)$. 


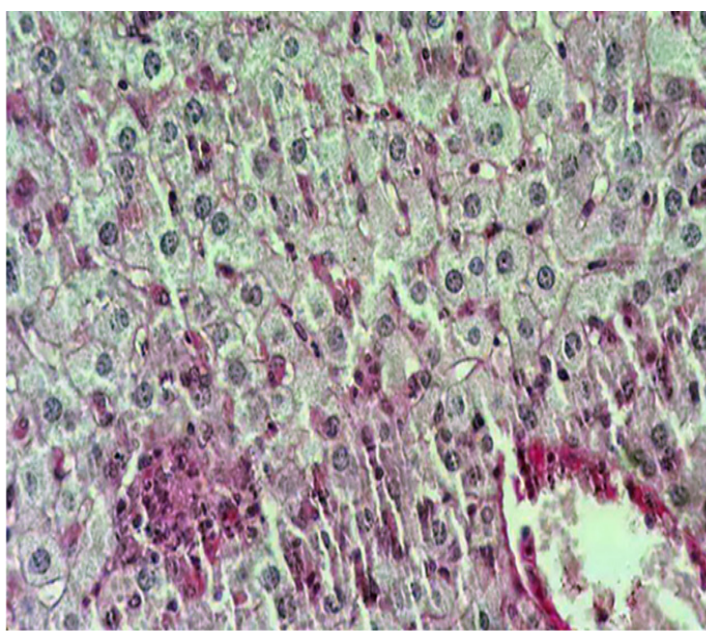

Figure 7 Cross histological section of liver tissue from castrated group stained with PAS showing a decrease in glycogen contents (X400).

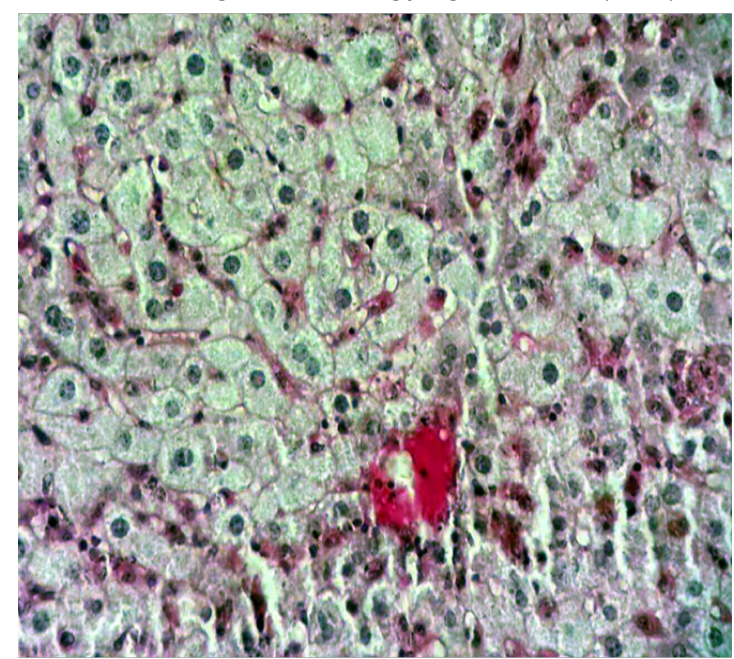

Figure 8 Cross histological section of liver tissue from intact group treated with $3 \mathrm{mg} / \mathrm{kg}$ F. hormones stained with PAS showing a decrease in glycogen contents (X400).

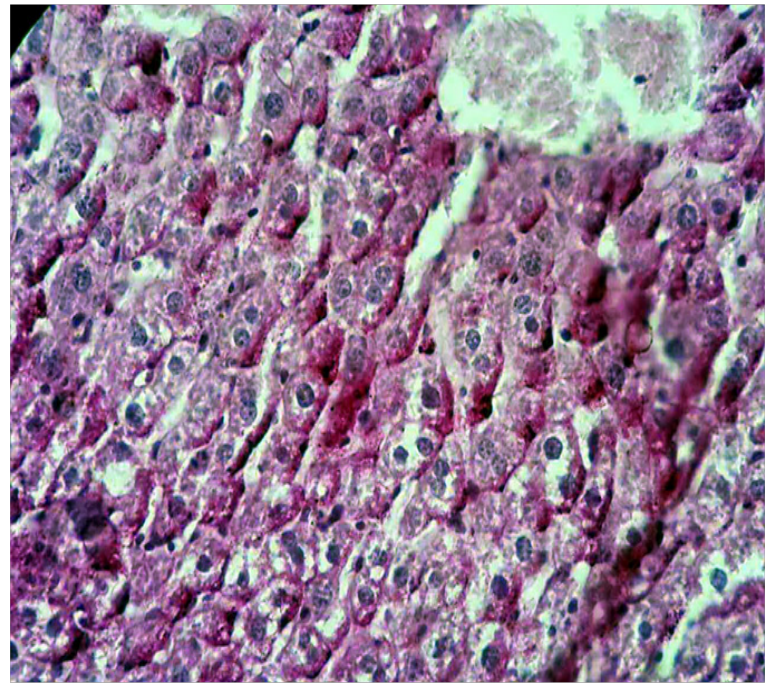

Figure 9 Cross histological section of liver tissue from castrated subject treated with $50 \mu \mathrm{g} / \mathrm{kg}$ testosterone stained with PAS showing normal glycogen contents, arrow indicated glycogen contents (X400).

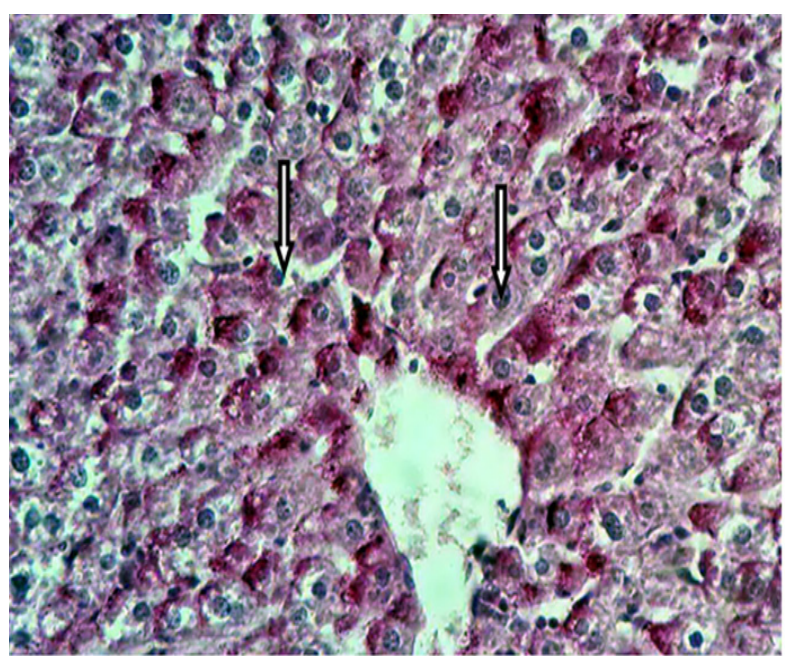

Figure 10 Cross histological section of liver tissue from castrated group treated with $10 \mu \mathrm{l} / \mathrm{g}$ grape juice stained with PAS showing normal glycogen contents, arrow indicated glycogen contents (X400).

\section{Discussion}

The present findings of liver frozen sections from castrated group showed a strong intensity $(+++)$ to Sudanophilia. These results can be attributed to the accumulation of intrahepatic lipids, which were mainly triglycerides. Frozen section of liver tissue from castrated group treated with testosterone showed a moderate intensity $(++)$ to Sudanophilia, these results may be due to the ameliorate role of testosterone in increasing number of Sudaniphilia through decreasing B-oxidation, free radicals and hepatic lipogenesis. It has been stated that low doses of testosterone in impairment functions, lead to accumulation of lipids with large number of Sudanophilia insides the hepatocytes..$^{38}$ the present findings are in agreement with the findings of ${ }^{39-41}$ who concluded that liver cells increased their affinity to Sudanophilia after treatment with testosterone.Also these findings are in concomitant with the findings of ${ }^{42}$ who stated thatthere was a significant increase in testosterone level in castrated subject treated with testosterone that resulted in an increase of Sudanophilia of liver cells.

The results of liver tissue from castrated group treated with grape juice showed a moderate intensity $(++)$ to Sudanophilia. These results may be due to the protective role of grape juice by increasing number of Sudanophilia through reducing the free radicals, B-oxidation that lead to increase the Sudanophilia in hepatocytes and return them to normal function and structure.

On the other hand frozen sections of liver tissue from intact group treated with $\mathrm{F}$. hormonis showed a strong intensity (+++) to Sudaophilia. These findings can be attributed to many factors: it might be due to anti androgenic activity of F. hormonis that inhibit the testosterone level in the tissues which lead to increased adipose lipolysis and hepatic lipogenesis. However, F. hormonis may have direct action on the gluconeogenesis or disruption of normal process within either the hypothalamic pituitary axis or gonads. ${ }^{43}$ Reported that subjects treated with F. hormonis extract resulted in a testicular tuberculosis and suppression of spermatogenesis. Studies by ${ }^{44,45}$ are also in agreement with these findings who showed that intragastric administration of $\mathrm{F}$. hormonis resulted in several pathological effect such as: colon adenocarcinoma, decrease of blood elements, and reduction in body weight, decline in social aggression, abnormalities 
of sperm and many other marked physiological and biochemical disruption.

According to the present findings of glycogen contents from castrated group showed decreased amount of glycogen contents. These results are in agreement with the findings of ${ }^{46}$ who stated that, there is a relationship between low level of testosterone and insulin sensitivity, increased hyperglycemia lead to decrease in glycogen contents in skeletal muscle and liver.On the other hand insulin resistance was confirmed by the decreased expression of key regulator genes of glucose up- take and utilization in muscle of androgen deficient in castrated mice as compared to the control groups. The present findings are in agreement with, ${ }^{47}$ who concluded that, testosterone deficiency caused adiposity, insulin resistant, B-pancreatic cells failure, increased lipolysis and hepatic lipogenesis with decreased glycogen contents.

The histological sections from castrated group treated with testosterone revealed a normal intensity to glycogen contents. This result may be due to those metabolic effects of testosterone and regulating FAS level in subcutaneous tissue also decreased adipose lipolysis which considered the main source in hepatic steatosis. ${ }^{48,49}$ reported that testosterone replacement in castrated animals maintain the glycogen contents within normal value. These findings are in agreement with others, ${ }^{47,50}$ who stated that testosterone replacement in castrated rate restore the castration effects and glucose homeostasis.

The findings of liver sections from castrated group treated with grape juice also showed a normal glycogen contents these results may be due to the protection effects of grape juice against oxidative stress that was caused to increase glutathione and catalase in the liver tissues and/or grape juice may has an antioxidant and free radical scavenging activities, therefore protecting against oxidative stress and replenishing the reduced glutathione contents. This administration of grape juice ameliorated and enhanced the antioxidant defense against castration induced oxidative stress. These results are in agreements with the findings of, ${ }^{51,52}$ concludedthat the potential beneficial role of grape juice in preventing oxidative stress-mediated damage and strengthening antioxidant defense mechanisms, with an increase in the antioxidant status of animals.

Histological sections of liver tissue from intact group treated with F. hormonis showed a decrease in glycogen contents. These results may be due to the anti-androgenic effects of $\mathrm{F}$. hormonis and its role in impairment the glycogen contents through conversion all the glucose to lipids by impairment in glycogenesis which cause to decrease the glycogen contents. To our knowledge there was no research work has been conducted to evaluate the effect of F. hormonis on theliver tissue and these findings may be due to that cholestasis or biliary obstructive in bile duct might play some pathogenic role indecreasing glycogen contents. The present results are in agreement with, ${ }^{43}$ reported that the intragastric application of F. hormonis extract caused inhibition of normal growth in testes and other male sexual organs. As well as, this treatment caused cystic swelling and tuberculosis in the testes.

\section{Conclusion}

From the achieved results of this study, we can conclude the following: Both castration and F. hormonis have reversible effects on liver cells. Through increasing their affinity to Sudanophilia as well as decreasing their glycogen contents. On the other hand testosterone and/or grape juice have dramatic effects for restoring liver cells to normal structure in castrated subjects.

\section{Acknowledgments}

None.

\section{Conflicts of interest}

The authors declare there are no conflicts of interest.

\section{Funding}

None.

\section{References}

1. Wang H, Thorling CA, Liang X, et al. Diagnostic imaging and therapeutic application of nanoparticles targeting the liver. Journal of Materials Chemistry B. 2015;3(6):939-958.

2. Kaplan JB, Kalra A, Biggins SW. Liver Anatomy and Function. In: Radiation Therapy for Liver Tumors. Springer: Cham; 2017:3-11.

3. Carollo V, Di Giancamillo A, Vitari F, et al. Immunohistochemical aspects of Ito and Kupffer cells in the liver of domesticated and wild ruminants. Open Journal of Veterinary Medicine. 2012;2(3):129-136.

4. Kubes P, Jenne C. Immune Responses in the Liver. Annual review of immunology. 2018.

5. Homady $\mathrm{MH}$, Khaled $\mathrm{M}$ Khleifata, Khaled A Tarawneh, et al. Reproductive toxicity and infertility effect of Ferula hormonis Extracts in mice. Theriogenology. 2002;57(9):2247-2256

6. Liqaa O Ali, Merza H Homady. Testosterone replacement protects against Non-Alcoholic Fatty Liver Disease in Castrated male mice. Journal of Global Pharma Technology (JGPT). 2018;10(9-10):37-46.

7. Moya D, González LA, Janzen E, et al. Effects of castration method and frequency of intramuscular injections of ketoprofen on behavioral and physiological indicators of pain in beef cattle. $J$ Anim Sci. 2014;92(4):1686-1697.

8. Sawhney P. Burdizzo Versus Pinhole Castration In Bucks And Cattle Calves. Nanaji Deshmukh, Veterinary Science University Jabalpur.' 2016.

9. Harada N, Hanaoka R, Hanada K, et al. Hypogonadism alters cecal and fecal microbiota in male mice. Gut microbes. 2016;7(6):533-539.

10. Júnior R.R, Rincon KS, Jesus ICG, et al. Testosterone deficiency prevents left ventricular contractility dysfunction after myocardial infarction. $\mathrm{Mol}$ Cell Endocrinol. 2018;460:14-23.

11. Jia Y, Yee JK, Wang C, et al. Testosterone Protects High Fat/Low Carbohydrate Diet Induced Non-Alcoholic Fatty Liver Disease in Castrated Male Rats Mainly via Modulating ER Stress. Am J Physiol Endocrinol Metab. 2018;314(4):E366-E376.

12. Jones TH. Testosterone deficiency: a risk factor for cardiovascular disease. Trends Endocrinol Metab. 2010;21(8):496-503.

13. Saleem H, Al-Djaily AN, Homady MH. Effect of Methanolic Leaf Extract of Moringa oleifera on some Biochemical Markers in obesity induced rats. Research Journal of Pharmaceutical, Biological and Chemical Sciences. 2016;7(3).

14. Homady MH, Majeed AA. Histochemical and Pheromonal Components of Mouse Preputial Gland in Relation to Estradiol Treatment. European Journal of Scientific Research. 2015;129:179-186.

15. Kelly DM, Jones TH. Testosterone and obesity. Obesity Reviews. 2015;16(7):581-606.

16. Saad F. The emancipation of testosterone from niche hormone to multisystem player. Asian J Androl. 2015;17(1):58-60. 
17. Homady MH, AL-quraishi LO, Tanya S Salih, et al. The Intra Gastric Effects of Grape Juice on Histological Structure of Liver Tissue in Castrated Treated Mice. Journal of Human Anatomy. 2020;4(1):1-6.

18. Hua X, Sun Y, Zhong Y, et al. Low serum sex hormone-binding globulin is associated with nonalcoholic fatty liver disease in type 2 diabetic patients. Clin endocrinology. 2014;80(6):877-883.

19. Homady MH, Khleifat KM, Tarawneh KA, et al. Reproductive toxicity and infertility effect of Ferula hormonis extracts in mice. Theriogenology. 2002;57(9):2247-2256.

20. Aragno M, Tagliapietra S, Nano GM, et al. Experimental studies on the toxicity of Ferula communis in the rat. Res Commun Chem Pathol Pharmacol. 1988;59(3):399-402.]

21. Yuan H, Ma Q, Ye L, et al. The traditional medicine and modern medicine from natural products. Molecules. 2016;21(5):559.

22. Merza H Homady, Hussein Abdul Kadhim, Khalida K Abbas AlKelaby, et al. Cytotoxic activity of compounded anthracycline against rhabdomyosarcoma canser cell line. Plant Archives. 2018;18(1):941-946.

23. Ananga A, Obuya J, Ochieng J, et al. Grape Seed Nutraceuticals for Disease Prevention: Current Status and Future Prospects. In Phenolic Compounds-Biological Activity. InTech. 2017.

24. Hasona NA, Alrashidi AA, Aldugieman TZ, et al. Vitis vinifera Extract Ameliorate Hepatic and Renal Dysfunction Induced by Dexamethasone in Albino Rats. Toxics. 2017;5(2):11.

25. Georgiev V, Ananga A, Tsolova V. Recent advances and uses of grape flavonoids as nutraceuticals. Nutrients. 2014;6(1):391-415.

26. Homady MH, Majeed AA. Pheromonal compounds and Histologica Alteration of Castrated Mose Preputial Gland in Relation to Eruca sativa Extract. Biochem Cell Arch. 2017;17(2):703-707.

27. Cosme F, Pinto T, Vilela A. Phenolic Compounds and Antioxidant Activity in Grape Juices: A Chemical and Sensory View. Beverages. 2018;4(1):22.

28. Martin DP. Guidelines for Animal Care and Use in Biomedical Research Current Protocols in Pharmacology. 2010;49(1):A-4.

29. Homady MH, Majeed AA. Histochemical and pheromonal components of mouse preputial gland in relation to F. hormonis treatment. Research $J$ of Pharmacy and Technology. 10(12):1-9.

30. National Research Council. Guide for the care and use of laboratory animals. National Academies Press. 2010.

31. Al-Fatlawi AA. Effects of Some Heavy Metals especially $\mathrm{Cr}$ and $\mathrm{Ni}$ on some Histological and Physiological Parameters in male Mice Ph.D. Thesis, College of Science, Kufa University, Iraq. 2015.

32. ALquraishi LO. Immunohistochemical and Ultrastructural studies of liver mice and its relation to endocrine factors. Ph.D. Thesis, College of Science, Kufa University, Iraq. 2018.

33. Park YK, Park E, Kim JS, et al. Daily grape juice consumption reduces oxidative DNA damage and plasma free radical levels in healthy Koreans. Mutat Res. 2003;529(1):77-86.

34. Homady MH. Infertility and carcinogenity of Ferula hormonis. A.R.T. And Science. 2003;3(1):5-8.

35. Rodrigues AD, Scheffel TB, Scola G, et al. Neuroprotective and anticonvulsant effects of organic and conventional purple grape juices on seizures in Wistar rats induced by pentylenetetrazole. Neurochemistry international. 2012;60(8):799-805.
36. Fedchenko N, Reifenrath J. Different approaches for interpretation and reporting of immunohistochemistry analysis results in the bone tissue-a review. Diagnostic pathology. 2014;9(1):221.

37. Homady $\mathrm{MH}$. The influences of some medicinal plant extracts on the aggressively and fertility of male mice. Philippine $J$ Science. 2002;130(3):119-126.

38. Hamodi HM, Abed AA, Taha AM. Comparative Anatomical, Histological and Histochemical Study of the Liver in Three Species of Bird Raf J Sci. 2013;24(5):12-23.

39. Zemanova Z, Strnadova M, Jirsova Z, et al. Occurrence of lipids in the liver of the hypertriglyceridemic rats. Biomedical Papers of the Medical Faculty of Palacky University in Olomouc. 2009;153(1):37-39.

40. Merza H Hamady. Preputial Gland and its Role in Pheromone Production in Relation to Some Endocrine Factors. Journal of stem Cell Biology and transplantation. 2017;1(1):4.

41. Souza CEAD, Stolf AM, Dreifuss AA, et al. Characterization of an alcoholic hepatic steatosis model induced by ethanol and high-fat diet in rats. Brazilian Archives of Biology and Technology. 2015;58(3):367-378.

42. Nikolaenko L, Jia Y, Wang C, et al. Testosterone replacement ameliorates nonalcoholic fatty liver disease in castrated male rats. Endocrinology. 2014;155(2):417-428

43. Homady MH. Changes in the testicular and preputial gland structure of mice related to influence of Ferula hormonis extract. The sciences. 2001;1(3):108-112.

44. Khelifat K, Homady MH, Tarawneh KA, et al. Effect of Ferula hormonis extract on social aggression, fertility and some physiological parameters in prepubertal male mice. Endocr J. 2001;48(4):473-482.7

45. Khleifat K, Homady MH. Histopathological effects of Ferula Hormonis Extract on the colon of male mice. Mu'tah Lil-Buhuth wad-Dirasat (Natural and applied Sciences Series). 2002;17(2):47-58.

46. Rato L, Alves MG, Dias TR, et al. Testicular metabolic reprogramming in neonatal streptozotocin-induced type 2 diabetic rats impairs glycolytic flux and promotes glycogen synthesis. J Diabetes Res. 2015:973142.

47. Dubois V, Laurent MR, Jardi F, et al. Androgen deficiency exacerbates high-fat diet-induced metabolic alterations in male mice. Endocrinology. 2015;157(2):648-665.

48. Homady MH, Hussain H, Tarawneh K, et al. Effects of applications of some medicinal plant extracts used in Jordan on social aggression and gonadal function in male mice. Aggressive Behavior. 2000;3(3):27:221.

49. Finkelstein JS, Lee H, Burnett-Bowie SA, et al. Gonadal steroids and body composition, strength, and sexual function in men. $N$ Engl J Med. 2013;369(25):2457.

50. Nucci RAB, Teodoro ACDS, Krause Neto W, et al. Effects of testosterone administration on liver structure and function in aging rats. The Aging Male. 2017;20(2):134-137.

51. Homady MH. Changes in the testicular and preputial gland structures of mice related to influence of Ferula hormonis extract. The Sciences. 2001;1(3):108-112.

52. Ali DA, El-Din NKB, Abou-El-magd RF. Antioxidant and hepatoprotective activities of grape seeds and skin; against Ehrlich solid tumor induced oxidative stress in mice. Egyptian Journal of Basic and Applied Sciences. 2015;2(2):98-109? 